\title{
A metáfora antropofágica em Todas as vezes que dissemos adeus de Kaká Werá Jecupé
}

\section{Carline Cunha Ramos Quaresma}

\begin{abstract}
As one of the first Indigenous authors in Brazil to record the myths of his own people in book form, Kaká Werá Jecupé occupies a privileged space of enunciation vis-à-vis other writers who have published books about Indigenous verbal arts. His books rescue the ancestral memory of the Guarani people and carry with them the differential of having been written by someone who belongs to this culture. According to Kaká Werá Jecupé, until the publication, in 1994, of the first edition of Todas as vezes que dissemos adeus, Brazilian Indigenous culture had always been presented through the voices of anthropologists, indigenists, or social scientists. In this paper I focus on the resonances in the book of the anthropophagy metaphor-a trace of Indigenous culture drawn by Oswald de Andrade as a political gesture for a discussion of questions of the relationship between self and other. I take it as a point of departure to discuss Kaká Werá Jecupé's position, living "between two worlds", and his mission to reveal his age-old tradition to so-called civilization, promoting the opening of a dialogue between cultures.
\end{abstract}

Keywords: anthropophagy; translation; creative writing; ethnopoetics; rewriting

Résumé : Kaká Werá Jecupé, un des premiers auteurs autochtones brésiliens à réunir dans un livre les mythes de son peuple, occupe une position d'énonciation privilégiée vis-à-vis des autres écrivains qui ont publié des livres au sujet des arts verbaux autochtones. Son livre vient au secours de la mémoire ancestrale du peuple guarani et se différencie des autres ouvrages en ce qu'il a été écrit par un auteur lui-même issu de cette culture. Selon Kaká Werá Jecupé, jusqu'en 1994, date de la première édition de Todas as vezes que dissemos adeus, la culture brésilienne autochtone avait toujours été présentée par les anthropologues, les partisans des causes autochtones ou les chercheurs en sciences sociales. Dans cet article, je m'intéresse aux résonances, dans le livre, de métaphores anthropophagiques - une trace de la culture autochtone qui est, selon Oswald de Andrade, un geste politique dont le but est d'occasionner un questionnement sur les relations entre soi et l'autre. II s'agit là de mon point de départ pour parler de la posture de Kaká Werá Jecupé, qui habite "entre deux mondes ", et de sa mission qui consiste à révéler la tradition millénaire de son peuple à la prétendue civilisation, et à encourager l'ouverture d'un dialogue entre les cultures.

Mots clés : anthropophagie; traduction; création littéraire; éthnopoétique; réécriture

Resumo: Um dos primeiros autores indígenas do Brasil a registrar em um livro os mitos de seu próprio povo, Kaká Werá Jecupé ocupa um lócus de enunciação privilegiado, comparado a outros escritores que publicaram livros sobre as artes verbais indígenas. Seus livros resgatam a memória ancestral do povo Guarani, trazendo o diferencial de terem sido escritos por alguém que pertence a essa cultura. De acordo com Kaká Werá Jecupé, antes da pulicação, em 1994, da primeira edição do livro Todas as vezes que dissemos adeus, a cultura indígena brasileira era sempre apresentada pelas vozes de antropólogos, indigenistas ou cientistas sociais. Neste artigo, focalizo as ressonâncias da metáfora da antropofagia no referido livro - um traço da cultura indígena, proposto por Oswald de Andrade como um gesto político para a discussão das relações entre o " eu » e o outro. Tomo esta metáfora como ponto de partida para discutir a experiência " entre dois mundos » vivida Kaká Werá Jecupé, bem como sua missão de revelar sua tradição milenar à, assim chamada, civilização, promovendo a abertura de um diálogo entre culturas.

Palavras-chave : antropofagia; tradução; criação literária; etnopoética; reescrita

Resumen: Como uno de los primeros autores indígenas de Brasil en plasmar en forma de libro los mitos de su pueblo de origen, Kaká Werá Jecupé ocupa un espacio de enunciación privilegiado en relación con otros escritores que han publicado libros sobre el arte oral de los indígenas. Sus libros, obras que rescatan y transmiten la memoria ancestral del pueblo guaraní, tienen la cualidad de haber sido escritos por alguien que pertenece a esta cultura. Según Kaká 
Werá Jecupé, hasta la publicación, en 1994, de la primera edición de Todas as vezes que dissemos adeus, la cultura indígena brasileña había sido siempre presentada a través de la voz de antropólogos, indigenistas o especialistas en ciencias sociales. En este artículo abordo los ecos y resonancias que tiene en esta obra la metáfora antropofágica-un rastro de la cultura indígena destacado por Oswald de Andrade como gesto político para interrogar la relación entre el yo y el otro. Abordo esta metáfora como punto de partida para analizar la posición de Kaká Werá Jecupé, su condición de vivir "entre dos mundos", y su misión de revelar su tradición milenaria a la llamada civilización y promover la apertura del diálogo entre culturas.

Palabras clave: antropofagia; traducción; escritura creativa; etnopoética; reescritura

\section{Introdução}

O surgimento de projetos editoriais sobre as culturas indígenas produzidos pelos próprios membros dessas culturas ainda é recente. Por esse motivo, ainda são poucos os estudos relacionados à obra desses autores. No entanto, tais obras constituem acervo riquíssimo, e ao estudarmos uma em particular, qual seja, Todas as vezes que dissemos adeus (2002), de Kaká Werá Jecupé1, observamos aspectos bastante peculiares.

O escritor acima mencionado ocupa um espaço de fala privilegiado, pois foi um dos primeiros membros da cultura indígena a registrar os mitos dos povos originários brasileiros. Seus livros resgatam memórias ancestrais do povo Guarani e trazem o diferencial de serem escritos por alguém que pertence a essa cultura, compartilhando sua visão de mundo.

Este instigante livro de relatos autobiográficos chamou-nos a atenção desde o título, pois a frase "Todas as vezes que dissemos adeus" é melancólica, carrega em si a "delicada lição na arte de dizer adeus" (Jecupé, Todas as vezes 30 ). Refere-se a todas as vezes em que os povos originários, por razões as mais diversas, tiveram que partir de suas moradas para empreender viagens. Neste livro, Kaká nos conta as suas andanças e pontua: "Com o tempo, passei a andar pelas largas trilhas da cidade chamadas avenidas. Percorri suas florestas de aço e comi de seus frutos artificiais para descobrir os brasis" (Jecupé, Todas as vezes 37).

O livro nos fornece uma série de dados importantes acerca do autor. Soubemos, por meio dele, que Kaká é terapeuta e pahi, e como terapeuta, segue a linhagem dos pajés. Pahi é um difusor da memória sagrada e da cultura ancestral. Isto considerando, logo depreendemos que o papel que ele ocupa é essencialmente social e político. Nesse sentido, Kaká assume como verdadeira missão restaurar e difundir a memória cultural e a medicina ancestral de seu povo.

A partir de suas experiências pessoais, pesquisas, estudos e iniciações espirituais, desenvolveu um sistema próprio de difundir a medicina e a

\footnotetext{
${ }^{1}$ Kaká Werá Jecupé é de origem tapuia e foi posteriormente adotado pelos índios Mbyá Guarani da Aldeia Morro da Saudade em São Paulo. Escritor e conferencista no Brasil e no exterior, coordena ações humanitárias e ecológicas através do instituto Arapoty. É membro do recém fundado Conselho Mundial para Preservação da Diversidade Cultural e Tradições Ancestrais, com sede em Nova Delhi, Índia.
} 
cosmovisão indígena brasileira para a sociedade e atua através de vivências, palestras, cursos e seminários desde 1992.

Kaká observa, em prefácio à segunda edição de Todas as vezes que dissemos adeus (2002), que a cultura indígena brasileira foi sempre apresentada pela voz de antropólogos, de indigenistas ou de cientistas sociais, até a publicação da primeira edição deste livro, em 1994. Durante muito tempo, a "voz" outrora silenciada foi trocada por uma "voz emprestada", oriunda dos antropólogos. No entanto, por meio da obra de Kaká, temos acesso direto à voz Guarani, pois, agora, não se faz mais necessário que alguém lhe "empreste" a voz. Com ele deixam de existir os dois polos: o etnógrafo e o etnografado como pressupostos básicos da construção da própria etnografia.

Vale à pena lembrar que o fato de a cultura indígena ter sido sempre apresentada por outras vozes que não a própria voz indígena está relacionado à opressão sofrida por esses povos. Atualmente observamos o movimento emancipatório destes grupos, emancipação que, no entanto, é resultado de um processo de militância de várias lideranças indígenas, entre elas, Aílton Krenak, Davi Kopenawa e Álvaro Tukano, iniciado há pelo menos quarenta anos. Kaká, para dar a ver o seu mundo, assume seu espaço de fala como membro da cultura indígena Mbyá Guarani diante da cultura dita "civilizada", e passa então a ocupar o lugar antes preenchido por pessoas de fora da cultura na qual está inserido.

Segundo Jesus Martín-Barbero, semiólogo, filósofo e antropólogo colombiano (2014), a expressão privilegiada da dominação estaria na incapacidade de o oprimido falar por si mesmo da opressão. Desse modo, a alfabetização assume um caráter altamente subversivo, ao "desmontar" os mecanismos que obrigam o oprimido a usar o discurso do opressor, para que tenha acesso à sua própria palavra. Para Paulo Freire (1987), o fato de o oprimido ter sido durante tanto tempo silenciado, fez com que este, afinal, passasse a ser "hospedeiro" das ideias e costumes do opressor, legitimando-as, e em contrapartida, deslegitimando a sua própria cultura. Nesse sentido, é preciso reconhecer que falar não é somente se servir de uma língua, mas habitar um mundo em comum, fazê-lo lugar de encontro e combate, considerando de onde se fala, com quem se fala e para quê:

Aprender a falar é aprender a dizer o mundo, a dizê-lo com os outros, a partir da experiência de habitante da terra, uma experiência acumulada através dos séculos (Martín-Barbero 16).

Através da linguagem habitamos o mundo, nos fazemos presentes nele, o compartilhamos com outros homens. Por isso, na visão freireana (Freire) "analfabeto" não é o homem que não sabe ler e escrever, mas sim o homem impedido de dizer sua palavra. É através da educação, portanto, que os homens têm esse direito devolvido, para serem testemunhas e atores de sua vida e de seu mundo. A educação passa pela consciência dos oprimidos da sua situação no processo da opressão, ou seja, a educação conscientiza os oprimidos de sua própria condição. A alfabetização, neste sentido, é a devolução da palavra ao homem mudo/silenciado, sendo, inevitavelmente, transformadora dos campos político e social.

Kaká, a partir de suas experiências, entendera que a resistência passava pela compreensão mais profunda de outras culturas, principalmente a da 
chamada civilização. Fez-se necessário aprender o português para sobreviver, ou seja, foi preciso antropofagicamente "devorar o estrangeiro.

É curioso perceber como a antropofagia, um traço importante da cultura ameríndia, vai ser absorvida pelo modernismo da Semana de 22, transformandose em um gesto político. O Manifesto antropófago, de Oswald de Andrade, propõe, a partir da noção de primitivo, uma visão crítica de nossa herança cultural baseada na desconstrução de uma tradição ocidental e na apropriação criativa da antropofagia como prática de reinvenção, ou seja, propõe que esta sirva como um instrumento de análise, elaborado a partir da nossa própria cultura. Como ressalta o antropólogo brasileiro Eduardo Viveiros de Castro, o Manifesto Antropófago é "decolonial muito avant la lettre". No prefácio chamado "Que temos nós com isso?", do livro de Beatriz Azevedo intitulado Palimpsesto Selvagem ${ }^{2}$ (2016), Viveiros de Castro escreve que o "famoso bárbaro tecnizado de Keyserling", obviamente, não prescindia da técnica: "A antropofagia é tudo menos a absorção da metafísica messiânica europeia. Queremos, porém, a técnica 3". Segundo Haroldo de Campos:

A antropofagia oswaldiana [...] é o pensamento da devoração crítica do legado cultural universal, elaborado não a partir da perspectiva submissa e reconciliada do bom selvagem (idealizado sob o modelo das virtudes europeias no Romantismo brasileiro de tipo nativista, em Gonçalves Dias e José de Alencar, por exemplo), mas segundo o ponto de vista desabusado do "mau selvagem", devorador de brancos, antropófago. Ela não envolve uma submissão (uma catequese), mas uma transculturação; melhor ainda, uma transvalorização: uma visão crítica da história como função negativa (no sentido de Nietzsche) capaz tanto de uma apropriação como de desapropriação, desierarquização e desconstrução (Campos 234).

Do mesmo modo, podemos dizer que Kaká primeiro aprendeu a falar a língua da metrópole para posteriormente poder combater muitos dos discursos correntes acerca dos povos indígenas. Não se apropriou do idioma para escrever como forma de submissão, ao contrário, utilizou a escrita como instrumento de luta política e como ferramenta de fixação da sua memória cultural.

A pesquisadora Daniela Versiani indaga em seu artigo Autoetnografia: uma alternativa conceitual (2002), se o modelo tradicional de autobiografia cunhado no século XVIII iluminista ainda será eficaz para conferir visibilidade a sujeitos históricos que compartilham heranças socioculturais em constante circulação. Seria, portanto, necessário problematizar tal modelo, que sustentado na crença da plena "representação" de subjetividades, cristalizava

\footnotetext{
${ }^{2}$ Este livro faz uma análise crítica e pormenorizada do Manifesto Antropófago, aforismo por aforismo. O livro é "servido" em partes pela autora, seguindo a ordem de um grande banquete (aperitivo, entrada, primeiro prato, prato principal, banquete, sobremesa, cafezinho e licor) em que o manifesto é o "prato principal".

${ }^{3} \mathrm{O}$ "bárbaro tecnizado", expressão do filósofo alemão Hermann Von Keyserling incorporada por Oswald em seu projeto cultural, devora seus inimigos externos para adquirir, com nobreza e força, seu poder, conhecimento e técnica (ctd. em Azevedo 15).
} 
discursivamente o "Sujeito unívoco e estável" (Versiani 57). Segundo a autora, durante muito tempo acreditou-se que o homem ocidental, branco e europeu, poderia representar plenamente outras subjetividades, o que teria ocasionado, na realidade, o apagamento de qualquer subjetividade estranha a essa. No entanto, com a mudança de paradigma impulsionada pela alteração de consensos e interesses, associada à chegada às academias e departamentos universitários de sujeitos que se identificam com grupos minoritários, tornou-se urgente atribuir ao discurso autobiográfico um valor político que dê visibilidade às subjetividades de alguma forma a eles associadas. Tal percurso foi seguido por Kaká, que tendo estudado na cidade, em dado momento, passou a ser uma "ponte" entre a aldeia e a metrópole, tornando-se uma forte figura política dentro da luta das nações indígenas.

Ao fazer a leitura do Manifesto Antropófago de Oswald de Andrade, Azevedo (2016) atribui à palavra "manifesto" a dupla acepção de substantivo e adjetivo: a primeira é mais usual, ou seja, como grito de guerra, chamada à luta e a segunda - que se deve à feliz leitura da autora - como aquilo que se opõe ao oculto, ou seja, a manifestação do antropófago, a sua explicitação.

Os estudos relacionados à antropofagia oswaldiana nos levam a compreender que, para ele, não podíamos compartilhar do messianismo europeu, do antropologocentrismo cristão; precisávamos pensar-nos em nossos próprios termos. Segundo Viveiros de Castro, a antropofagia é uma "contraontologia, é o privilégio do haver ávido de alteridade" (ctd. em Azevedo 16). Chegamos então, dessa forma, à compreensão do que Oswald chamou de "consciente antropofágico", que se manifesta no desejo pelo outro, que ele cunhou no slogan "só me interessa o que não é meu. Lei do homem. Lei do antropófago". Viveiros de Castro (ctd. em Azevedo 16) esclarece que a antropofagia deve ser entendida como positividade transcendental e não como afirmação de uma identidade; apropriar-se do outro na tentativa de definir-se por meio dele, comer o inimigo não para "assimilá-lo", ou ainda, negá-lo para afirmar o Eu, mas transformar-se em outro, por meio dele, autotransfigurar-se com a ajuda do contrário.

Durante a vida, Oswald queixou-se várias vezes de que sua obra não era lida e suas ideias não eram aceitas, no entanto, a partir da encenação de o Rei da Vela, em 1967, ele tornou-se mais conhecido, sendo considerado por muitos como o "pai" do Tropicalismo e inspirador de críticos literários e do Cinema Novo. Dentre suas formulações, as relacionadas à antropofagia são as mais citadas, retomadas em muitas vertentes, por Zé Celso, Joaquim Pedro de Andrade, pelo concretismo, sendo citadas pela poesia marginal e pelo manguebeat e por outras diversas manifestações artísticas. Para Augusto de Campos, a antropofagia é a "única filosofia original brasileira". Viveiros de Castro afirma que "a Antropofagia Oswaldiana é a reflexão metacultural mais original produzida na América Latina até hoje" (Viveiros de Castro, Metafísicas Canibais 24).

\section{A metáfora antropofágica}

No Manifesto Antropófago, Oswald de Andrade propunha uma "concepção de mundo antropofágica" baseada na síntese dialética entre o mundo primitivo e o mundo "civilizado", entre o popular e o erudito, entre a liberdade e a técnica. Ancorado em uma potente recusa de modelos estéticos, éticos e políticos 
forjados pelo mundo ocidental moderno, Oswald aspirava por uma "revolução caraíba" capaz de reverter o vetor colonial e indigenizar nosso imaginário. Como fica expresso em sua tese $A$ crise da filosofia messiânica, para ele a própria vida "é devoração e a antropofagia, concepção filosófica da existência" (ctd. em Azevedo 106).

A antropofagia ritual é assinalada por Homero entre os gregos e segundo a documentação do escritor argentino Blanco Villata, foi encontrada na América entre os povos que haviam atingido uma elevada cultura - astecas, maias, incas. Na expressão de Colombo, comían los hombres (ctd. em Azevedo 107). Não o faziam porém, por gula ou por fome. Tratava-se de um rito que, encontrado também nas outras partes do globo, dá a ideia de exprimir um modo de pensar, uma visão de mundo, que caracterizou certa fase primitiva de toda a humanidade. Considerada assim, como Weltanschauung, mal se presta à interpretação materialista e imoral que dela fizeram os jesuítas e colonizadores. Antes pertence como ato religioso ao rico mundo espiritual do homem primitivo. Contrapõe-se em seu sentido harmônico e comunial, ao canibalismo que vem a ser a antropofagia por gula e também a antropofagia por fome, conhecida através das crônicas das cidades sitiadas e dos viajantes perdidos (ctd. em Azevedo 107).

Vemos então que Oswald busca situar a antropofagia em seu locus original4, salientando que esta pertence como ato religioso "ao rico mundo do homem primitivo”. Essa visão de mundo antropofágica é, assim pensamos, em grande medida a responsável por aquilo que o etnólogo brasileiro Eduardo Viveiros de Castro chama de "a inconstância da alma selvagem", ou seja, a expressão de um modo de ser onde "é a troca, não a identidade, o valor fundamental a ser afirmado" (Viveiros de Castro, Eduardo Viveiros 206). Trata-se, portanto, de um aspecto constitutivo do pensamento ameríndio.

Segundo o antropólogo Renato Sztutman ${ }^{5}$, Eduardo Viveiros de Castro pôde constatar que a antropofagia é, como já havia proposto Oswald de Andrade, debruçado na literatura informativa do século XVI, "mais que mera refeição cerimonial. Trata-se de uma metafísica que imputa um valor primordial à alteridade e, mais do que isso, que permite comutações de ponto de vista, entre eu e o inimigo, entre o humano e o não humano.

Analisando diversos textos de Oswald de Andrade, presentes no trabalho de Beatriz Azevedo (2016), observamos que, para ele, o homem sempre foi o

\footnotetext{
${ }^{4}$ Interessante lembrar que Montaigne em "Des cannibales" já apontava para a necessidade de se pensar a antropofagia não a partir da visão europeia, mas a partir de sua lógica interna. "Contra o universalismo cosmográfico e os fantasmas coloniais ele (Montaigne) coloca a ideia de que o estranho deve ser compreendido absolutamente a partir de si mesmo, e compreender isso significa também compreender a si próprio. Pela primeira vez mostra-se aqui com clareza aquela convergência entre estranho externo e interno que se tornará central para a compreensão da identidade e da alteridade da modernidade (Kiening 187).

${ }^{5}$ Prefácio da Coleção Encontros Eduardo Viveiros de Castro. Rio de Janeiro: Beco do Azougue, 2007, p.13.
} 
animal devorante por excelência, "mas as religiões de salvação o desidentificaram, levando-o aos piores desvios (catolicismo, teosofia, puritanismo, comunismo ideológico). (Azevedo 135).

Sobre essa "desidentificação", que se deve, em grande parte, à colonização ou à "vitória do branco no Novo Mundo", Silviano Santiago 6 afirma: "se deve menos à razões de ordem cultural do que ao uso arbitrário da violência e à imposição brutal de uma ideologia" (Santiago 11). Adiante, em seu ensaio $O$ entre-lugar do discurso latino-americano, ele pontua que "A maior contribuição da América Latina para a cultura ocidental vem da destruição sistemática dos conceitos de unidade e de pureza". Ou seja, o deslocamento da cultura europeia para fora do "seu lugar" provocou uma série de transformações nos elementos feitos e imutáveis que os europeus exportavam para o Novo Mundo. Dentro dessa lógica, sem o desvio das normas ocidentais estabelecidas aqui, nossa produção artística seria mera cópia, ou silêncio. Tal silêncio seria o desejável pelo imperialismo cultural, para o qual, na melhor das hipóteses, deveríamos produzir um eco das vozes do conquistador. Portanto, para Santiago, "falar, escrever, significa: falar contra, escrever contra." (Santiago 17). Essa atitude subversiva, proposta por Santiago, nos incita a questionar a centralidade da racionalidade europeia, e a fazer eco a outras vozes que por opressão foram silenciadas. Nesse sentindo, a denúncia contundente presente em O Selvagem, de Couto de Magalhães, é mordaz:

Tanto os conquistadores espanhóis e portugueses, como os jesuítas, consideram o selvagem um instrumento de trabalho, uma espécie de mina, cuja exploração disputaram encarniçadamente. Tudo quanto eles escreveram a respeito do selvagem americano, a não ser as primeiras impressões de viagem, é dominado por esse pensamento fundamental. Estava nos interesses dos conquistadores deprimir o mais possível a raça conquistada; com efeito, só assim eles podiam legitimar os medonhos atos de barbária [sic] que cometeram. Para poder matar os índios como se mata uma fera brava, poder tomar-lhes impunemente as mulheres, roubar-Ihes os filhos, criá-los para a escravidão, e não ter para com eles lei alguma de moral e nem lhes reconhecer direitos, era mister acreditar que nem tinham ideia de Deus, nem sentimentos morais ou de família. A história um dia fará plena justiça a essas asserções. (Azevedo 157)

Pensamos, portanto, que a publicação dos livros indígenas e a quebra do discurso único são, de certa forma, uma justiça histórica conquistada. Vale considerar o que Azevedo (2016) assinala: a força da antropofagia oswaldiana resiste justamente em nos lembrar que o "homem primitivo", o "homem nu", ou seja, o antropófago, vive em todos nós não como passado ancestral a ser recuperado, não enquanto "identidade nacional", mas como uma dimensão vital

\footnotetext{
${ }^{6}$ O entre-lugar do discurso latino-americano In: Uma literatura nos trópicos. Rio de Janeiro: Rocco, 2000.
} 
e necessária. A cultura antropofágica é o processo de reinvenção infinita, ela permanece porque pode mudar.

\section{A antropofagia das lideranças indígenas}

Os povos indígenas, principalmente a partir da década de 1960, passaram a pensar em sua situação e em que estratégias de resistência deveriam seguir, e com isso concluíram: "Agora não devemos lutar para resgatar aquilo que nós éramos antes, agora é hora de analisar o que fizeram conosco e pensar no que vamos fazer daquilo que fizeram de nós" (Jecupé, Kaká Werá 119). Ou seja, de certo modo, "não é o retorno do índio à taba, mas sim o primitivo tecnizado", como disse Oswald. Essas reflexões engendraram a estratégia surgida primeiramente entre os Xavantes e entre os Guaranis de

[...] aos poucos tomar as ferramentas da sociedade chamada civilizada, seus códigos, tecnologias, pedagogias, e utilizá-las como modo de veicular os valores e a visão de mundo das matrizes ancestrais do Brasil. Afinal, embora sufocada, a essência e o espírito de cada cultura nativa continua presente sob o disfarce da colonização (Jecupé, Kaká Werá 120).

No ensaio "Por um universalismo descentrado: considerações sobre a metáfora antropófaga", que faz parte do livro Antropofagia hoje? (2011), o escritor e diplomata João Almino destaca a radicalidade da proposta antropófaga, que não se ocupa apenas de dizer que somos uma mistura de culturas, nem uma conjugação entre o primitivo e o civilizado. Lembremo-nos que o Manifesto Antropófago, lançado na Revista de Antropofagia em 1928, suscitou uma grande discussão acerca da cultura brasileira, exercendo grande influência sobre o modernismo brasileiro. Ao questionar-se sobre o que nos une, Oswald conclui que o que nos une é o outro, e pelo fato do outro existir e de termos interesse por ele, queremos, sobretudo, devorá-lo. Desse modo a cultura brasileira não está voltada somente para as "suas raízes", estando não somente aberta ao mundo, como preparada para devorá-lo: "Nossa abertura é feita através de bons dentes e de um grande estômago. Somos capazes de devorar o outro e, com isso, de regenerar nosso próprio tecido" (ctd. em Rocha 56). É importante dizer que não devemos assumir a atitude inocente e acrítica de defender os particularismos, sejam eles geográficos, raciais, étnicos ou de gênero. Uma sociedade diversificada deve entender suas várias tradições, considerando que o confronto e o diálogo são fundamentais, inclusive para reforçar a tradição e a cultura local:

É fundamental sobretudo aceitar como universais os valores democráticos e o princípio do direito. Os índios Chiapas se rebelam defendendo direitos e falando em democracia, utilizando, portanto, como fundamento, valores da cultura ocidental precisamente para preservar suas próprias tradições (ctd. em Rocha 61).

Para resistir Kaká veio percorrer as florestas de aço da dita "civilização" e dela tomou ferramentas para travar a sua própria luta: "Comi de vosso cérebro: agora 
como manda a tradição, ofereço o meu espírito" (Jecupé, Todas as vezes 17). Oferecer seu espírito é partilhar com a sociedade os saberes milenares de sua cultura. Segundo Almino, a metáfora antropófaga pretende resolver o dilema nacional/cosmopolita, já que o antropófago digere o estrangeiro. Existe na antropofagia uma abertura para o outro, pois nesse processo é fundamental a assimilação do outro para a transformação do próprio. João Cezar de Castro Rocha, em "Oswald em cena: o Pau-Brasil, o Brasileiro e o Antropófago", ressalta: "pretendemos estimular novas abordagens da obra de Oswald de Andrade, buscando entender a antropofagia como um exercício de pensamento cada dia mais necessário nas circunstâncias do mundo globalizado, pois a antropofagia permite que se desenvolva um modelo teórico de apropriação da alteridade" (Rocha 12). Kaká inclui, em seu trabalho, variados esforços para desestigmatizar a noção presente na sociedade de que o índio é apenas aquele que vive na floresta, distante da chamada civilização. Nesse sentido, faz-se importante considerar que havendo contato dos povos indígenas com outras culturas, os valores próprios desses povos não se perdem, ao contrário, podem se fortalecer, pois o contato com o "diferente" faz com que possamos ver com maior clareza o que somos. Sérgio Paulo Rouanet, filósofo e diplomata, no "Manifesto Antropófago II", fala do antropófago e da questão da "identidade" com uma nota de humor: Não temos nenhum medo de comprometer nossa identidade, primeiro porque identidade é coisa de antropólogo, e costumamos comer todos os antropólogos, e segundo porque nossa identidade, na medida em que existe, é constituída precisamente pelo que não é nosso, pelo que vem de fora, pelo que recebemos [...] O que somos é alimentado pelo que não somos. Por isso nossa identidade é sempre negativa. Aberta, nômade, inacabada, provisória (ctd. em Rocha 52).

Kaká, ao incorporar a ferramenta da escrita em sua militância, amplia as possiblidades de difundir o conhecimento ancestral da cultura Guarani. A ideia principal do seu projeto é dar voz "àqueles que trazem a marca da ancestralidade em sua jornada de vida", para que haja o efetivo respeito à pluralidade de culturas, considerando os índios como atores desta sociedade. Para termos uma ideia da duração de sua atuação como militante ${ }^{7}$, o jornalista Vinícius Gorczeski, em entrevista realizada com Kaká, constata: "Desde que tinha uns 16 anos Kaká Werá amassa barro atrás de gente branca para reforçar a cultura indígena nas escolas e nas aldeias" (Jecupé, Kaká Werá 57). Só a antropofagia nos une, observou Oswald de Andrade em seu Manifesto Antropófago.

Kaká, portanto, apropria-se da cultura "branca" como forma de resistência e renovação de forças numa verdadeira metáfora antropofágica:

Meus espíritos instrutores (os Tamãi) empurraram-me na boca do jaguar, essa yauaretê chamada metrópole, creio que como prova, para que aprendesse e comesse dessa língua e cultura de pedra e aço. Foi assim que comi o pão que a civilização amassou. Sobrevivi. Por isso, devorei o cérebro dessa cidade (Jecupé, Todas as vezes 16).

\footnotetext{
${ }^{7}$ Kaká Werá Jecupé é responsável pelo Instituto Arapoty, que promove a difusão das tradições indígenas, atua como palestrante na UNIPAZ, Universidade Holística da Paz; foi candidato ao senado em 2014.
} 
Em Todas as vezes que dissemos adeus (2002), o autor comenta que "firmou o compromisso de traduzir a vermelha 'escritura-pintura' de seu corpo para o branco corpo desta 'pintura-escrita', e que "aceitou por inteiro a missão de ser um porta-voz à surda metrópole com seus ornamentos de néon e a beleza cosmética" (Jecupé, Todas as vezes 16). Seus pais, para que ele sobrevivesse, o fizeram comer da cultura "branca", matriculando-o em uma escola, mesmo que isso significasse para eles correr o risco de sacrificar a cultura "vermelha" (Jecupé, Todas as vezes 13).

Um dia, sem mais nem porquê, uma senhora convencera meu pai a matricular-me na escola que se instalara morro abaixo, de nome Professor Manuel Borba Gato. Não quis. O pai me disse que era uma maneira de nos defendermos. Perguntei o que era a escola. Me respondeu que era o lugar onde se riscava com traços o que se falava, e que qualquer um podia dizer exatamente o que se havia falado olhando para aqueles traços, mesmo que se passassem sóis e luas. Isso me deixou fortemente encantado (Jecupé, Todas as vezes 31 ).

Na apresentação do livro Tupã Tenondé, a criação do Universo, da Terra e do Homem segundo a tradição oral Guarani (Jecupé, Tupã Tenondé), ele relata que em uma das visitas do etnólogo paraguaio Leon Cadogan ${ }^{9}$ e do professor Egon Shaden ${ }^{10}$ à aldeia do cacique Pablo Werá, este Ihes disse:

Os últimos grandes sábios pajés estão indo embora para a morada dos nossos "Pais Primeiros". Existe o perigo de que, ao desaparecerem por um tempo desta morada terrena, as palavras sagradas fiquem esquecidas na fala Guarani, e sem elas a verdadeira cultura ancestral degenera. Um de nossos pajés disse que mais adiante, quando o espaço abraçar um novo círculo de tempo, Tupã renascerá no coração do estrangeiro. De modo que eu gostaria que registrassem nossas palavras mais formosas, para que, quando nós formos, elas possam acordar os futuros corações (Jecupé, Tupã Tenondé 20).

\footnotetext{
8 Para Derrida, entende-se por escritura todas as modalidades de escrita que sejam fundamentalmente não fonéticas, mesmo que a escrita fonética tenha se constituído num tempo posterior da história da escrita (ctd. em Corsseto, s/d). Neste caso, Kaká firma o compromisso de traduzir sua cultura "vermelha", "escritura pintura" que não baseava-se em uma escrita fonética, parecendo aqui referir-se à pintura corporal ou iconográfica indígena, para a cultura "branca", escrita no papel, "branco corpo desta 'pintura-escrita"', ou seja, a escrita fonética, que reproduz os sons da fala.

${ }^{9}$ Leon Cadogan foi um importante antropólogo e etnólogo paraguaio pioneiro na tradução dos cantos sagrados Mbyá Guarani para o espanhol em 1959 no livro intitulado "Ayvu Rapyta: textos míticos de los Mbyá-Guarani del Guairá.

10 Antropólogo brasileiro que possibilitou a primeira publicação dos cantos sagrados Mbyá Guarani no Boletim 227 de Antropologia da Faculdade de Filosofia, Letras e Ciências Humanas da Universidade de São Paulo.
} 
Vemos, portanto, a urgência em se fazer o registro da cultura ancestral Guarani, para que a memória desse povo não caia no esquecimento. Em Todas as vezes que dissemos adeus (2002), Kaká narra episódios marcantes de sua adolescência. Tais episódios são cruciais para entendermos como foi se moldando em seu espírito a futura militância com a qual se envolveria profundamente:

Foi assim que adolesci. Vi apodrecer a água que nos banhava. Vi sumirem as aves que adornavam a arte guarani. Vi rasgarem a terra com dentes de aço para romper estradas e delimitar propriedades dentro de sítios sagrados guarani. Vi a roça ficando escassa para o cultivo do alimento. $\mathrm{E}$, quando os guaranis precisaram descer a aldeia Morro da Saudade para trocar seu artesanato pelo que comer, vi pagarem esmolas e ouvi a expressão: - Sujos, nem banho tomam (Jecupé, Todas as vezes 40).

\section{Relações entre antropofagia e tradução}

De acordo com o crítico literário francês Antoine Berman (2002), em A prova do estrangeiro: cultura e tradução na Alemanha romântica "[...]a essência da tradução é ser abertura, diálogo, mestiçagem, descentralização. Ela é relação, ou não é nada" (Berman 17). Operando esse diálogo entre culturas Kaká fortalece a cultura indígena e nos convida a conhecer sua riqueza e beleza:

Agora, de acordo com a tradição, faço a fogueira, ponho aromáticos preparados de ervas, galhos secos; e lhe convido a ouvir ao pé dela. Sente-se. Devo alertar-lhe para que fique à vontade, esse ritual é para melhor ouvir ne'e porãs, as belas falas, as falas sagradas, de alguns anciões que por essa história hão de passar, e são cheias de lições antigas do povo guarani. E invento essa fogueira para seguir corretamente a tradição, pois tudo o mais veio do já acontecido e aqui se reconta. Fatos que fazem parte da ruínas do passado, que venho partilhar para partir; para que as chamas as transformem no pó e a boa reflexão do que foi dito possa servir de húmus para a humanidade (Jecupé, Todas as vezes 37 ).

Berman, trata ainda do "sistema de perdas e ganhos" numa tradução e entre os ganhos da tradução de uma obra está o fato de que ela "potencializa o original" e faz "aparecer" alguma coisa do original que não aparecia em sua língua de partida. A mudança provocada potencializa a obra, regenerando-a, pois, "na língua de chegada, a tradução desperta possibilidades ainda latentes e que só ela [...] tem o poder de despertar" (Berman 28). Citando Goethe: "A força de uma língua não está em rejeitar o estrangeiro, mas em devorá-lo" (ctd. em Berman 29).

Para o teórico alemão Edwin Gentzler (2008) a antropofagia pode ser considerada uma metáfora dos estudos pós-coloniais, promovendo um olhar próprio sobre as questões relacionadas à cultura brasileira de modo a superar 
algumas limitações impostas pela colonização. Nesse aspecto, é importante observar que os primeiros relatos feitos pelos europeus sobre a antropofagia exploravam um sentido negativo, associando-a a um comportamento selvagem e sanguinário. No Brasil, todavia, a antropofagia foi vista, mais frequentemente, em termos positivos, simbolizando a resistência da raça ameríndia que em virtude de seu "consciente antropofágico" sobreviveu, apesar da colonização. Gentzler (2008) ressalta que a maior contribuição do Brasil para os estudos da tradução foi a noção de antropofagia, por apontar novos caminhos a serem percorridos. A metáfora antropofágica de Oswald de Andrade, relida por Haroldo de Campos, passou a ser reconhecida como a "via brasileira" nos estudos da tradução em nível mundial.

Kaká comenta que o livro Todas as vezes que dissemos adeus (2002) opera revelando a visão de mundo de sua cultura e

mostrando [...] iniciações interiores, [...] percepções deste mundo que se desmorona e busca se reconstruir a cada dia. A busca de raízes mais profundas do ser. Por isso ele foi escrito no ritmo das inquietações do ser. No ritmo das memórias fragmentadas que lutam por formar uma coesão. Memórias que se agrupam para tentar encontrar o si mesmo de cada um e a importância das raízes ancestrais neste "si mesmo" (Jecupé, Todas as vezes 10).

Essa busca pelo "si mesmo", segundo Berman (2002), faz parte da "experiência de alteridade no mundo", para se ter acesso ao que, "sob o véu de um tornar-se outro, é na verdade, um tornar-se si" (Berman 82).

O movimento da "alteridade no mundo" é interessante, e de "mão dupla". Ao passo que nos permite vislumbrar diversos aspectos de uma determinada cultura, também permite que essa mesma cultura observe melhor a si mesma. O poder "protéico e ilimitado de se lançar na alteridade", segundo Berman (Berman 64), é muito produtivo culturalmente, por partir do paradoxo "segundo o qual quanto mais uma comunidade se abre ao que não é ela, mais ela tem acesso a si mesma" (Berman 64).

Interessante é que Kaká demonstra estar consciente desse movimento e das possibilidades que este oferece:

[...]eu vim para mostrar a nudez do meu povo. A claridade do coração. Eu vim para nos despirmos. Para descobrirmos os brasis. Para descobrirmos os brasileiros. Para conversarmos juntos ao pé do fogo (Jecupé, Todas as vezes 17).

Na narrativa de uma de suas experiências transcendentais, ele comenta que foi convidado pelos seus ancestrais a ajudar "àqueles que se dizem civilizados", escrevendo sobre a antiga sabedoria "que os tempos guardaram na secreta memória da terra" (Jecupé, Todas as vezes 93). Percebemos, portanto, que os projetos editoriais de Kaká Werá são eivados de motivações políticas, como a luta pela preservação da memória e cultura indígena, a assunção da missão de porta-voz das comunidades indígenas na luta pela preservação do planeta e a transmissão de valores a serem compartilhados com a chamada civilização, promovendo a abertura de um diálogo entre culturas. 
No percurso de leitura do célebre ensaio haroldiano percebemos que ao devorar a cultura estrangeira Kaká realiza movimento semelhante ao expresso na metáfora machadiana comentada por Campos (2006):

Machado de Assis, por exemplo. O grande e inclassificável Machado, deglutidor de Laurence Sterne e de incontáveis outros (é dele a metáfora da cabeça como um "bucho de ruminante", onde, como lembra Augusto Meyer [...] todas as sugestões, depois de misturadas e trituradas, preparam-se para nova mastigação, complicado quimismo em que já não é possível distinguir o organismo assimilador das matérias assimiladas. (Campos 236237)

Ao entender que precisaria "devorar" a cultura estrangeira para difundir a sua própria cultura, Kaká passou a frequentar a escola e sob o encantamento de poder fixar o que é dito "mesmo que se passassem sóis e luas" (Jecupé, Todas as vezes 31), aprendeu a ler e escrever. Em um de seus relatos ele diz:

Sonhei que os Tamãi deram-me a incumbência de contar um pouco da minha história, da minha vida entre dois mundos, e de revelar alguns mistérios da tradição milenar ensinada pelos Antigos, os que aqui habitavam desde sempre. [...] Cumprindo a tarefa nesse relato, para tingir o que até então no mundo tem parecido 'intingível', a mistura do vermelho sobre o branco resultando na cor da vida (Jecupé, Todas as vezes 16).

Neste trecho Kaká afirma viver "entre dois mundos" e ter sido incumbido de revelar alguns mistérios da tradição milenar, sua tarefa é "tingir o que parecia 'intingível", misturar a "cultura vermelha" à "cultura branca", operando um diálogo que resulte na "cor da vida".

Considerando a importância da produção indígena, vale mais uma vez citar Haroldo de Campos (2006), pois ele nos chama a atenção para a necessidade de se pensar a diferença e a ruptura em vez do traçado linear: uma tradição a operar como "contravolução" como uma "contracorrente" oposta ao cânone "prestigiado e glorioso" (Campos 237).

Para ele, o que é relegado à margem do caminho, desprezado e subjugado, aquilo que é coletado sob o nome de "antiqualhas" é que carrega o que "há de vivo na tradição", ou seja, algo que está impregnado de potência. (Campos 237). Campos propõe uma historiografia como "gráfico sísmico da fragmentação eversiva", e não como "homologação tautológica do homogêneo" (Campos 237). Uma tradição em que seja possível reunir a poesia "sonorista tupi" e o "haicai japonês", como nos manifestos oswaldianos (Campos 245). Pois bem, Kaká promove o encontro entre a cultura indígena e a não indígena, e o quimismo proveniente desse encontro é extremamente profícuo.

Kaká, ao ocupar o lugar de escritor, ciente da importância, valor e potencial da cultura indígena, nos comunica que partilha conosco "fatos que fazem parte das ruínas do passado", para que "as chamas as transformem no pó e a boa reflexão do que foi dito possa servir de húmus para a humanidade." (Jecupé, Todas as vezes 37). 


\section{Considerações Finais}

Consideramos que há no ato tradutório de Kaká Werá Jecupé o compromisso de afirmar o valor e a beleza de sua cultura, bem como o de fixá-la. Nesse sentido, Kaká partilha conosco sua tradição milenar tendo consciência de que o contato entre culturas é algo que faz parte do movimento da humanidade e que, como ele mesmo ressalta, nenhuma cultura evolui sem contato. Trata-se de promover o diálogo e a abertura para vivificar a diferença. Os ensinamentos contidos na memória ancestral Guarani nos dão uma visão de mundo, na qual todas as coisas estão interligadas: o homem, a natureza, a terra. Visão bastante diferente da disseminada pela civilização moderna e capitalista. Kaká, como membro da cultura Guarani, nos revela aspectos únicos de maneira muito particular, pois cada cultura constitui sua própria visão de mundo - sua expressão artística, política e espiritual -, manifestando de maneira muito particular suas ações e ritos, formas de pensar, conhecer, e sentir. Somos, enquanto brasileiros, povo de influência cultural variada, portanto é imprescindível que haja um espaço onde essas diferentes culturas possam dialogar. Cada cultura deve encontrar uma forma de se conectar com outras culturas, pois esse diálogo é fértil, integrador e libertador. A abertura consciente que Kaká promove nos torna mais cônscios da riqueza cultural do povo indígena brasileiro, nos dando uma maior noção do lugar de onde viemos, considerando que possuímos, também, uma cultura milenar. Como afirma João Cezar de Castro Rocha em Oswald em cena: O pau-brasil, o brasileiro e o antropófago (Rocha 11) o significado mais instigante da antropofagia está no fato de que é apenas através do outro que conhecemos um pouco de nós mesmos. Na busca pelo direito de expressar seus valores culturais e de ampliar seu conhecimento incorporando os saberes da sociedade - sem que isso signifique desqualificar os seus próprios saberes - e da dignidade de serem tratados como cidadãos, e não como estrangeiros em suas próprias terras, um grupo de lideranças indígenas passou a fortalecer um movimento de militância que se iniciou há pelo menos trinta anos, entre essas lideranças estava Kaká Werá Jecupé. Kaká nos diz que uma tradição cultural não muda, no sentido de apagar-se para dar lugar a outra coisa, mas evolui, por um sistema de renovação e síntese com outras relações culturais, ecológicas e sociais. Segundo ele, a produção editorial dos índios é relativamente nova no Brasil, iniciou-se na década de 1990, o que não significa dizer que os índios não escreviam ou que não haviam aprendido os códigos de comunicação da sociedade que aqui aportou no século XVI. Ocorre que a educação implementada pelos padres jesuítas visava a desvalorizar a cultura ancestral dos povos nativos. De acordo com Kaká, hoje existem mais de cinquenta escritores indígenas em atividade, trazendo à sociedade em geral a expressão de seus pensamentos e de suas respectivas produções, promovendo com isso um maior entendimento sobre seus costumes, valores e visão de mundo. Ele avalia que muito se falou das tradições indígenas, porém, por mais esforços que tenham empreendido aqueles que se dispuseram a tratar dessas questões, devemos considerar que até o início da década de 1990 esse olhar ocupava o ponto de vista alheio. Considerando que não há povo imune às mudanças, pois estas são próprias da condição humana, seria inocência ou leviandade esperar que os povos indígenas permanecessem para sempre isolados, sem contato com a sociedade envolvente, principalmente constatando-se que a sanha do capital 
tem invadido, desde muito tempo, os espaços onde eles habitam. Nesse processo, muitas etnias foram extintas, outras se transformaram ou foram transformadas. Kaká ressalta que precisamos apoiar e colaborar com o resgate da dignidade das raízes que formaram o povo brasileiro, afinal, como ele afirma, quem melhor entende de índio é o próprio índio. Desse modo, todo o seu trabalho está voltado para a difusão e reconhecimento da "voz" indígena.

\section{Referências}

Almino, João. "Por um universalismo descentrado: Considerações sobre a metáfora antropófaga." Antropofagia Hoje?, editado por Jorge Ruffinelli e João Rocha, Editora Realizações, 2011, pp. 55 - 62

Andrade, Oswald. A psicologia antropofágica. Rio de Janeiro, 1929.

Azevedo, Beatriz. Antopofagia - Palimpsesto Selvagem. São Paulo, Cosac Naify, 2016.

Berman, Antoine. A prova do estrangeiro: cultura e tradução na Alemanha romântica. Bauru, SP: EDUSC, 2002.

Campos, Haroldo de. "Da razão antropofágica: diálogo e diferença na cultura brasileira." Metalinguagem e outras metas: ensaios de teoria e crítica literária, São Paulo: Perspectiva, 2006.

Corsseto, Patrizia. "Escritura e Escrita." s/d. Disponível em: https://lacaneando.com.br/escritura-e-escrita/. Acessado em: 18 de Fevereiro de 2017.

Freire, Paulo. Pedagogia do Oprimido. 17aㅡ ed. Rio de Janeiro, Paz e Terra, 1987.

Gentzler, Edwin. Translation and identity in the Americas: New directions in translation theory. Routledge, 2008.

Jecupé, Kaká Werá. As fábulas fabulosas de lauaretê. São Paulo, Peirópolis, 2007.

---. Kaká Werá. Rio de Janeiro, Beco do Azougue editorial. Coleção Tembetá, 2017.

---. O trovão e o vento: um caminho de evolução pelo xamanismo tupi-guarani. São Paulo, Polar Editorial: Instituto Arapoty, 2016.

---. Todas as vezes que dissemos adeus. $2^{\underline{a}}$ ed. São Paulo, Triom, 2002.

---. Tupã Tenondé: A criação do Universo, da Terra e do Homem segundo a tradição oral Guarani. São Paulo, Pierópolis, 2001.

Kiening, Christian. O sujeito selvagem: Pequena Poética do Novo Mundo. São Paulo, EDUSP, 2014.

Martín-Barbero, Jesús. A Comunicação na Educação. São Paulo, Contexto, 2014.

Rocha, João Cezar de Castro. "Oswald em cena: O pau-brasil, o brasileiro e o antropófago." Antropofagia Hoje?, editado por Jorge Ruffinelli e João Rocha, São Paulo, Editora Realizações, 2011, pp.11 - 18

Rouanet, Sergio Paulo. "Manifesto Antropofágo II." Antropofagia Hoje?, editado por Jorge Ruffinelli e João Rocha, São Paulo, Editora Realizações, 2011, pp. $49-54$

Santiago, Silviano. "O entre-lugar do discurso latino-americano." Uma literatura nos trópicos: ensaios sobre dependência cultural, Rio de Janeiro, Rocco, 2000. 
Versiani, Daniela Beccaccia. Autoetnografia: uma alternativa conceitual. Porto Alegre, Letras de hoje, V. 37, ํo 4, 2002, p. 57-72.

Viveiros de Castro, Eduardo. Araweté os deuses canibais. Rio de Janeiro, Jorge Zahar Editor, 1986.

---. A inconstância da alma selvagem. São Paulo: Cosac Naify, 2002.

---. Eduardo Viveiros de Castro - Encontros. Rio de Janeiro: Beco do Azougue, 2007.

---. Metafísicas Canibais: Elementos para uma antropologia pós-estrutural. São Paulo, Cosac Naify, 2015. 